\title{
Sentidos sobre a Amizade Entre Travestis: Construção de Repertórios Interpretativos
}

\author{
Rita Martins Godoy Rocha ${ }^{1, *}$ \\ ${ }^{1}$ Universidade de São Paulo, São Paulo, SP, Brasil \\ Emerson Fernando Rasera ${ }^{2}$ \\ ${ }^{2}$ Universidade Federal de Uberlândia, Uberlândoa, $M G$, Brasil
}

\begin{abstract}
RESUMO - Considerando a necessidade de outros olhares sobre a complexidade do universo das travestis, este estudo objetiva descrever e analisar os repertórios interpretativos sobre as relações de amizade entre elas. Participaram 10 travestis do sudeste brasileiro. A entrevista individual semiestruturada foi o recurso metodológico escolhido, apoiada pelo caderno de campo. O estudo se baseou nas propostas de análise do discurso construcionista social. Cinco repertórios interpretativos sobre amizade foram identificados: Babado; Batalha; Família; Segredo e Uó. O uso dos repertórios, em diferentes arranjos, apresenta a maneira como as travestis contam sobre si, seja ressaltando seus potenciais, seja legitimando sentidos de marginalidade e estigma. Esses sentidos criam a possibilidade de existência entre elas e podem subsidiar a construção e implementação de intervenções e políticas direcionadas a essa população.
\end{abstract}

Palavras-chave: travestis, amizade, sexualidade, construcionismo social

\section{Meanings of the Friendship among Transvestites: Construction of Interpretative Repertories}

\begin{abstract}
Considering the need of alternative views of the complex universe of transvestites, this study aims to describe and analyze the interpretative repertoires of friendship used by them. The participants were ten transvestites who live in the southeast of Brazil. Individual semi-structured interviews were conducted and field notes were taken. The data analysis was based on discourse analysis as proposed by social constructionism. Five repertoires of friendship were identified: Babado, Batalha, Family, Secret and Uó. The use of repertoires, through different arrangements, shows how transvestites tell about themselves, either emphasizing their potentials or legitimizing meanings of marginality and stigma. These meanings create the possibility of existence between them and may encourage interventions and policies targeted to this population.
\end{abstract}

Keywords: transvestites, friendship, sexuality, social constructionism

Na busca por compreender o universo das travestis, mostra-se um risco prender o conceito do que seja "travesti" em um vocabulário natural e universal. Em diferentes contextos, seja o da militância, o científico, ou o do senso comum, os discursos sobre as travestis estão diretamente vinculados aos discursos sobre transexuais, homossexuais, mulheres e drag queens (Leite Junior, 2008). Essas delimitações fluidas entre as nomenclaturas aparecem nos discursos auto referenciados por travestis em um movimento que implode uma identidade fixa, demonstrando a recriação constante desse gênero e das matrizes identitárias no seu entorno.

Historicamente, as travestis estão associadas à androgenia. Da antiguidade grega até o período renascentista, a ambiguidade sexual relacionava-se diretamente à vivência mítica, cujo trânsito entre feminino e masculino era tido com algo mágico, poderoso e significativo culturalmente. Apenas no fim do século XVII, com a Modernidade, as travestis começam a ser situadas no lugar do desvio

* Endereço para correspondência: Centro Universitário de Araraquara, Uniara, Coordenação do Curso de Psicologia, Rua Carlos Gomes, 1338, Centro, Araraquara, SP. Brasil. CEP: 14.801-340.E-mail: ritamgr@usp.br patológico, o que reverbera até a atualidade (Leite Junior, 2008). Na Classificação Estatística Internacional de Doenças e Problemas Relacionados à Saúde - CID-10 (Organização Mundial de Saúde, 2009) essas pessoas são vinculadas ao diagnóstico de travestismo bivalente (F. 64.1) e de travestismo fetichista (F. 65.1).

Ao mesmo tempo, as travestis demarcam hoje um lugar questionador por transgredir a lógica do sexo naturalizado e por desejar e reinventar um feminino. Apesar da vulnerabilidade e da convivência com o que Butler (2003) chama de abjeção, as travestis traduzem a vida numa busca pelo feminino, que segundo elas, dão sentidos às suas práticas (Benedetti, 2005). O conceito de abjeção remete às zonas inóspitas em que se identificam os corpos que não estão de acordo com a lógica inteligível do sistema binário de gênero, ou seja, zonas que estão fora do "domínio dos sujeitos", termo que Pelúcio (2007) associa às travestis após terem seus corpos modificados. Nesse lugar (in)subordinado, as travestis buscam, desde 1993, uma organização política no Brasil por meio de encontros nacionais e regionais. Em 2000, fundaram a Articulação Nacional de Travestis, Transexuais e Transgêneros (ANTRA) com o objetivo de demarcar um espaço de diálogo e defesa dos seus direitos (Carvalho, 2011). 
No campo científico, os trabalhos produzidos sobre as travestis, de forma geral, encontram predominantemente o diálogo com a Antropologia e o método etnográfico, demonstrando a construção do feminino travesti, os contornos da linguagem compartilhada (o Bajubá) e a prostituição como marcador dessa categoria de gênero (Benedetti, 2005; Kulick, 2008; Silva, 1993). O Bajubá ou "bate-bate" é a linguagem utilizada pelas travestis que mesclam palavras em português e, também, léxicos oriundos do ioruba-nagô, língua de origem africana. É dinâmica e utilizada de forma restrita entre elas, apenas compartilhada e decifrada entre pessoas consideradas confiáveis e integradas ao grupo. A prostituição aparece como um meio de sociabilidade marcante no processo de tornar-se travesti, ainda que não se faça regra toda travesti ser profissional do sexo (Pelúcio, 2007). Nesse contexto, elas encontram um espaço legítimo para o aprendizado da "montagem", para realizarem as modificações corporais e também por serem reconhecidas pelo grupo (Benedetti, 2005). No entanto, outras possibilidades para além do complexo rua-travesti-prostituição-aids ainda não são abordadas com destaque nas etnografias, dado o caráter central e historicamente importante desse complexo.

A Psicologia, por sua vez, caminha tímida no campo teórico sobre as travestis, sendo ainda marcante a visão psicopatológica das travestis e transexuais (Cardoso, 2005). A Psicologia Social tem, por outro lado, contribuído com as discussões de gênero de forma mais crítica, especialmente desde o marco histórico do texto de Unger (1979), que problematizou o uso que os psicólogos faziam do termo gênero, restringindo as diferenças sexuais às diferenças biológicas e estruturais. Conforme Nuernberg (2008), foi entre as décadas de 1980 e 1990 que se iniciou um processo de abertura do foco biologizante e biomédico prevalente na Psicologia para as análises simbólicas, históricas e sociais. No campo específico da travestilidade, trabalhos como de Peres (2005) e Garcia (2009) merecem destaque por pontuarem recortes críticos sobre os diferentes modos de estigmatização nas expressões de vida das travestis, bem como no enfrentamento da intolerância sofrida por elas.

As etnografias (Benedetti, 2005; Kulick, 2008; Silva, 1993) ressaltam, de forma geral, uma gramática compartilhada sobre as travestis em que o "barraco" é marcante, a rua é o espaço marginalizado e a prostituição o destaque. São essas as práticas discursivas que comumente conformam e visibilizam as travestis.

Com a mesma ênfase discursiva, buscamos direcionar este estudo para outras relações que parecem despercebidas nos textos acadêmicos: um cotidiano que envolve a ida à padaria, ao serviço de saúde, a espaços de lazer, que abrange as escolhas de companhias para esses momentos, o retorno à escola, a parceria em situações de adoecimento e abandono. Interessados por esse contexto, e buscando demarcar outros jeitos possíveis de dizer sobre as travestis, investigamos as relações de amizade entre elas.

Nesse enquadre, Foucault (2010) colabora e problematiza que a amizade é uma possibilidade de reinvenção estética das relações institucionalizadas em nosso tempo, reconhecendo que o que existe no campo das relações está "longe de preencher todos os espaços possíveis" (Foucault, 1981, p. 39). Nesse mesmo sentido, Ortega $(1999,2002)$, em uma leitura histórica, mostra como a amizade sofre um declínio de problematizações na sociedade moderna por ser integrada cada vez mais à família nuclear, com vistas à incorporação do amor ao matrimônio, à medicalização da homossexualidade, bem como à passagem de um dispositivo de parceria para $\mathrm{o}$ da sexualidade e do erotismo.

A amizade, como um campo potencial de análise, convida à reflexão sobre a infinidade de relações que poderiam existir se fossemos capazes de encontrar suas próprias leis não nas instituições, mas em outras lógicas e em outras formas de produção de sentidos (Foucault, 2010). Tal apontamento ressoou neste estudo, que pretendeu a partir de um grupo específico, no caso travestis, identificar formas de dizer sobre as relações de amizade num universo pouco investigado, onde os códigos e linguagens são reinventados a todo o momento.

As travestis não vivenciam o convencional, o que promove um constante movimento de questionar e legitimar as estruturas de família, educação, trabalho e gênero. Assim, elas precisam, citando Foucault (1981, p. 38): "inventar de A a $Z$, uma relação ainda sem forma que é a amizade". Nessa invenção, delimitada pelo encontro, as falas sobre amizade podem ser atravessadas por sentidos originados em diferentes momentos históricos e relacionados a diferentes retóricas, seja cristã, amorosa, familiar, legitimando-as ou mesmo questionando-as.

Diante das contribuições teóricas ressaltadas, fomos convidados a revisitar as relações sociais entre as travestis, com o olhar que busca referenciá-las pelos discursos de amizade. O objetivo deste estudo foi, de forma geral, descrever e analisar os sentidos da amizade entre as travestis. Além disso, buscamos, especificamente: a) identificar critérios utilizados para a avaliação dessas relações; e b) compreender as variações dessas relações nos diferentes espaços vivenciados por elas.

\section{Método}

Neste estudo, pautamos o entendimento sobre a sexualidade situado historicamente e distante de compreensões que visam atribuir uma essência estável ou atribuir categorias patologizantes ao sexo. O recorte foi fundamentado no Construcionismo Social (Nogueira, 2001; Paiva, 2008; Weeks, 1999), o qual abrange uma abertura para a emergência de sentidos, fundamentando-se em uma análise discursiva para a compreensão da sexualidade e da travestilidade. Pelo viés teórico escolhido, compreendemos que: as práticas discursivas constroem realidades; o conhecimento é constituído a partir de sua inserção cultural; há uma ênfase na interação humana; e enfatiza-se uma postura reflexiva sobre as diferentes descrições do mundo (Gergen, 1997). Nesse sentido, os discursos produzidos entre e sobre as travestis possuem efeitos na existência dessa população.

\section{Contexto de pesquisa}

A região do Triângulo Mineiro, local onde o estudo foi realizado, ainda não contabilizou oficialmente o número de travestis residentes, mas é reconhecida como pólo 
importante de confluência dessa população (Teixeira, 2008). Em uma universidade local, foi constituído um Programa voltado para a promoção de saúde, educação e cidadania de travestis e transexuais, no qual atuamos como profissionais e colaboradores. As travestis participam dos serviços desenvolvidos pelo Programa, que abarcam oficinas, ambulatório, visitas domiciliares e distribuição de insumos. Em levantamento junto a 65 travestis participantes desse Programa, identificamos que elas se declaram numa idade média de 24 anos; 94\% se identificaram solteiras; $47 \%$ declaram ser brancas, $40 \%$ pardas/morenas e $12,5 \%$ negras; quanto a condições de moradia, cerca de $75 \%$ comunicaram residir em casas com outras travestis, $15 \%$ com a família e $2 \%$ sozinhas.

\section{Passos na construção do corpus e análise}

Realizamos entrevistas individuais e semi-estruturadas junto a 10 travestis participantes do referido Programa. As entrevistas foram áudio-gravadas, perfazendo um total de 15 horas e 30 minutos de gravação. Elas foram transcritas na íntegra e abarcaram temas como: a) identificação das participantes; b) relacionamentos interpessoais estabelecidos entre elas; e c) critérios para o estabelecimento das relações, em especial as de amizade. As participantes eram maiores de 18 anos, trabalhavam como profissional do sexo e moravam em uma pensão com outras travestis. O caderno de campo foi outra ferramenta metodológica utilizada como apoiador das análises.

O caminho escolhido para analisar o corpus se baseou na proposta de análise do discurso influenciada pelo Construcionismo Social (Potter \& Wheterell, 1987). A partir dessa proposta, realizamos a identificação de repertórios interpretativos, a qual seguiu o seguinte percurso: 1) transcrição das entrevistas realizadas, e identificação das primeiras impressões da análise do corpus; 2) leitura curiosa e atenta do material construído e do caderno de campo; 3 ) identificação de repertórios interpretativos usados durante a entrevista. Os repertórios interpretativos são "blocos linguísticos" utilizados pelas pessoas para construir suas versões dos fenômenos que participam (Burr, 1995; Potter \& Wheterell, 1987). Os repertórios são marcados por termos, metáforas, sinais, figuras de linguagem e imagens que são utilizadas na conversação. Eles não estão locados num nível individual, mas são compartilhados e estão disponíveis como um recurso social. As pessoas os utilizam para justificar alguma versão particular de um evento, para validar, ou questionar os próprios comportamentos, e para manter sua credibilidade na interação (Potter \& Wheterell, 1987). A identificação dos repertórios favorece a possibilidade de categorização, dando maior visibilidade ao processo de produção de sentidos.

Esta pesquisa foi aprovada pelo Comitê de Ética da universidade na qual se desenvolveu esta pesquisa. Ressaltamos que todos os procedimentos éticos foram respeitados e os nomes utilizados são fictícios. Seguindo outros pesquisadores (Benedetti, 2005; Pelúcio, 2007; Peres, 2005) e, respeitando a relação cotidiana estabelecida com o público, o estudo reitera o uso do artigo feminino para referenciar as travestis.

\section{Resultados e Discussão}

\section{Repertórios Interpretativos sobre as Relações de Amizade entre travestis}

Os repertórios de amizade aparecem em diferentes momentos na entrevista e, em geral, estão ligados às perguntas que exploram como se dá a construção das relações entre elas, os critérios para avaliação dessas relações e também para referenciar as pessoas importantes na história de vida. Por meio da análise realizada, foram identificados cinco repertórios interpretativos utilizados nas entrevistas, a saber: Amizade-babado, Amizade-batalha, Amizade-família, Amizade-segredo e Amizade-uó. A seguir, apresentaremos cada um dos repertórios e suas implicações.

\section{Amizade-babado}

Esse repertório é marcado por imagens e sentidos ligados ao agradável, ao raro, à sinceridade, à confiança, à lealdade, à proteção e à liberdade. O termo "babado" é usado entre as travestis pelo Bajubá e se refere, em geral, a algo muito bom ou a uma novidade (tipicamente, boa). Esse repertório remete ao sentido positivo do termo, de uma amizade que é dita em suas funções de reconhecer o vínculo construtivo entre elas. Ele é usado de diferentes formas, a saber: 1) ao dizerem de um critério utilizado no início do processo de fazeremse travestis, em um momento propício para constituição da amizade; 2) para contar dos meios de pertencimento e proteção mútua esse universo, em situações de dificuldade; 3) para falar de uma sociabilidade jocosa em que o humor é usado de maneira positiva e aceito.

O trecho a seguir aponta o primeiro uso do repertório, para dizer daquela travesti referenciada como a que acompanha, que compartilha a fome e as dificuldades, que inicia junto o processo de se tornar uma travesti, após o momento em que elas saem da casa da família:

\footnotetext{
E:...Como que foram construidos esses principais relacionamentos que cê tem hoje..

M: Eu conheci duas gays... eu conheci duas gays, a gente era bem novinha...

E: Duas gays?

M: Dois gays.

E: Dois gays...

M: Eu também era gayzinho na época, nós fomo pro Rio juntas, nós ficamos lá, fomos morar juntas. Ai, fui morar no Rio com essas duas bicha, ai nós ficamos... tivemos uma amizade maravilhosa...

E: Elas eram de (nome da cidade de origem da entrevistada)? M: Eram de (nome da cidade), somos de (nome da cidade).

E: Foi lá que tudo começou...

M: Que tudo começou pra nós três... Nós tivemos uma vida pra contá. Fomos pra Europa juntas. Elas foram primeiro
} 
depois eu fui. E dai ficou gravado na história como a gente era companheira, como a gente era amigas... (Margarida)

No trecho, a interação a partir das palavras "gay" e "bicha", bem como das negociações dos usos dos artigos masculinos para o feminino e vice-versa, marca o processo da construção da travesti compartilhado pelas três. O sentido é de um aprendizado compartilhado, um processo que envolve nomeações e sentidos que caminham para a predominância do feminino, passando pelo masculino. A travesti lança mão do repertório da Amizade-babado para valorizar aquelas que permanecem juntas no processo de transformação.

Nesse outro trecho está referenciado o uso da proteção significada entre as travestis, que referencia o próprio risco de vida e violência em potencial, conformando uma rede de sentidos em que ser parceira nos momentos de perigo e ameaça é compartilhado:

J: Quando eu arrumo uma confusão assim, algum caso de briga, ou na morte, aquilo acolá, ai todas tão em cima. Não aceita, sabe? Mas também elas não são de ficar em cima, sabe? Mas elas também não aceita as pessoas de fora fazer pouco da gente, né? Nem eu aceito com elas e nem elas comigo. Aí nesse aí a gente tem uma coincidência muito grande, sabe? Da ajuda... nossa uma ajuda... um problema, uma confusão, uma briga, todas tão em cima, vai dá o pau pra quebrar e vai... (Jasmin)

Esse repertório conforma o sentido de uma grupalidade entre as travestis: "nem eu aceito com elas e nem elas comigo". Elas produzem um sentido político diante da ameaça do outro que não é comum, ou mesmo diante de uma situação de perigo em que a morte é uma ameaça. Esses sentidos aparecem, comumente, no processo de construção identitária, e ressoam num significado de afirmação e até de rebeldia: "vai dar o pau pra quebrar", funcionando como um jeito de falar que mobiliza laços de solidariedade umas com as outras, reafirmando um sentido de proteção frente à situação de vulnerabilidade.

A união entre as travestis é significada quando uma delas é ameaçada por alguém fora do universo. Mas o delimitador maior e mais valoroso para o uso do repertório da Amizade babado é quando se trata de um problema com alguém do próprio meio. A amizade aparece confiável quando é relatado que uma travesti se arrisca por outra, entre "iguais".

Destaca-se nesse outro trecho o uso do humor como terceiro uso do repertório, por meio de brincadeiras no sentido crítico, mas que por ser entre travestis que mantêm um afeto positivo e respeitoso, ganham a autorização pela via do riso e da jocosidade:

F: Ai eu já procuro brincar com aquela que já me respeita. Como eu respeito. Aquela que eu sei que não é...

E: Como é que você brinca?

F: Como é que eu brinco? Ai. Brinco com elas, é no modo de

falar. Elas começa a brincar comigo, né?

E: Tipo falando o quê? Dá um exemplo da brincadeira?

F: Me chamam de vovó Piedade. Que a vovó Piedade bebe meio litro de conhaque na novela, né? (risos)

E: Ahhh. Vovó Piedade. (risos)

F: Ai eu xingo elas também. Tudo brincadeira. Entendeu? A gente ri...

\section{$R$ : Você xinga elas de quê? \\ E: Ai. Às vezes de bicha monstro... (Florinda)}

Vale demarcar que o uso desse repertório é comum na descrição da história da travesti sem remeter a um espaço específico para sua concretização, ou seja, demarca o início do processo de se reconhecer travesti e referencia um espaço de grupalidade/proteção/gratidão em uma situação de risco e adoecimento. No entanto, quando a casa e a rua são incluídas objetivamente como espaços de convivência, a amizade ganha outros usos e contornos.

\section{Amizade-batalha.}

A Amizade-batalha é um repertório identificado por imagens e sentidos associados à rua, ao companheirismo no trabalho, ao truque, à competição, à negociação, à fofoca, à prostituição e também à convivência na casa. $\mathrm{O}$ termo "batalha" é êmico nesse universo e faz referência ao trabalho das travestis, à ida à batalha, em especial, na prostituição. Em geral, nesse repertório, as travestis dizem de si mesmas, como vinculadas diretamente à prostituição, sentidos que confundem a transformação como travesti com a transformação como prostituta. Os usos desse repertório são identificados quando: 1) contam do processo de escolha de outra travesti para um trabalho em comum; 2) para referenciar os limites da amizade a depender do contexto de vida; 3) quando as travestis apontam os dilemas da rua e da necessidade de mantê-los velados.

O primeiro uso desse repertório é identificado na descrição de quando uma travesti chama a outra para trabalhar junto em um programa. Essa escolha não é feita, necessariamente, pela afinidade, confiança, ou por uma relação dita leal. A Amizade-batalha é usada ao situar a criação de critérios que começam na convivência em casa e influenciam uma parceria no trabalho. Para se referir ao contexto da rua, o sentido que prevalece é o da afinidade profissional:

E: Que cê consegue confiá? Me conta um pouco dessa...

M: Não... Não... que eu posso confiá não... Eu tenho assim, a P. como mais intima de eu chamar ela pros lugares, dá gente dormir junta, dá gente fazê uma suruba...

E: Rola isso né, também?

M: Rola... Rola... Porque tem travesti que me pega... tem cliente que me pega, ai fala: "ai eu quero vê você comendo uma amiga sua"... Ai muita das vezes ele escolhe, cê fala "não meu amô... Que eu já conheço a bicha lá de casa... como ela é... Ou ela é porca, ou ela é fresca, ou ela é cheia de tititi”, ou ela vai brigá com o cliente, então antes que aconteça isso... Apesar que a P. me deu o maior vexame ná última vez que a gente saiu... Chamei ela pra fazê uma suruba, ela deu um escândalo com o cliente... Ma é normal, eu já conheço, eu já conhecia... Já vi que isso poderia acontecê. [...] (Margarida)

O trecho a seguir permite analisarmos o uso do repertório Amizade-batalha no esforço de justificar momentos que não podem ser sinceras, a depender do contexto. Tal uso mostra que os sentidos variam no momento da entrevista segundo o espaço onde a amizade relatada é construída e mantida. 
As relações que poderiam ser potencialmente positivas, quando associados ao elemento "casa", são descritas como ameaçadas de alguma forma, em outros contextos. As travestis justificam esse uso pela dificuldade de construir uma amizade sincera convivendo com tantas travestis em diferentes espaços e na complexidade de temas associados a dinheiro, drogas, roupa e competição:

E: Você acha que é possivel ter amizade? É possivel?

A: Não. Tem muito coleguismo. Amizade não.

E: É e por quê? Açucena?

A: Queira ou não queira, entre elas, a disputa é muito acirrada, uma querendo ser melhor que a outra, uma querendo vestir melhor que a outra, uma ganha mais que a outra, então é um ambiente assim, que não dá pra ter amizade. Queira ou não queira é um tipo de um comércio. Ali o dinheiro fala mais alto. E: Entendi.

A: Então não tem afeto.

E: E quando tem? Você está me contando que tem, alguns momentos tem afeto...

A: Tem não, minha filha.

E: Até nestas que você confia?

A: Não, aí não, é diferente, entendeu? E (fala o nome da entrevistadora) ... Mas eu falo assim. Você me perguntou em termos geral? Não foi? (Açucena)

A negociação em torno das descrições sobre a amizade nesse repertório engendra o estabelecimento de um critério entre o que pode ser descrito no geral e o que é raro. O repertório da Amizade babado é utilizado para se referir a um grupo restrito, composto por uma, duas ou, no máximo, três travestis.

O repertório Amizade-batalha também aparece quando as travestis descrevem os dilemas da rua e da necessidade de tornar velados esses dilemas. Associa diretamente as relações das travestis a uma característica do grupo: "quem tem telhado de vidro não joga pedra no vizinho". Ou seja, por meio desse repertório, as travestis comunicam relações compostas por pessoas que, de forma geral, não são "santas", incluindo elas mesmas, e essa descrição cria um sentido de tolerância diante do universo e entre elas:

\section{E: X9 é o que, Perpétua?}

P: Ai, fofoqueiro. Tipo assim. Uma coisa que eu não gosto. A gente tá na rua Rita, tipo assim, eu tenho teto de vidro...eu tenho um teto de vidro igual qualquer uma.

E: Claro...

P: Eu não roubo, eu num faço nada de errado. A não ser... eu tô nessa colocação (termo êmico: uso excessivo de drogas). Se alguém comentar e a (dona da pensão) escutar não vai ser novidade pra (dona da pensão) vai ser uma coisa pra me pegar. Mas eu não quero esse constrangimento. Entende? Pra que eu vou falar de uma? Sendo que a outra também pode falar de mim. (Perpétua)

Por meio desse repertório, as travestis falam de um reconhecimento dos próprios limites relacionais, nos contextos da casa e da rua. Ele abre espaços para dizer de relações que são possíveis a partir da negociação entre o que a outra faz, o que a própria entrevistada faz e qual o limite de comunicar isso ao grupo. Ou seja, no repertório Amizade-batalha existe uma cumplicidade que não se dá pela idealização de um afeto, nem no sentido de pertencimento ao grupo, mas pela necessidade do contexto que abarca, ao mesmo tempo, sentidos de competição, fofocas, trabalho e dilemas afetivos. Para tanto, a função desse repertório é dizer dos conflitos, mas buscando sentidos adaptativos aos mesmos.

\section{Amizade-família}

O repertório da Amizade-família é marcado por um vocabulário organizado em torno de palavras como mãe, pai, cafetina, união, irmã, irmão, casa, cama, conselhos, a casa-pensão. Esse repertório é utilizado em momentos das entrevistas em que as travestis falam de suas relações associadas à formação de uma "grande família", incluindo o vocabulário da irmandade nessas relações. Os usos desse repertório abarcam: 1) dizeres sobre a familiaridade e o sentido de lar atribuído à casa-pensão onde residem; 2) descrições sobre a dona da pensão, ora na função maternal, ora contraposta à figura de uma autoridade sobre a travesti; 3 ) a construção da nova relação que muda da família de origem para esse novo sentido inventado pelas travestis.

Por meio desse repertório, a produção de sentidos sobre a amizade situa um espaço centrado na casa-pensão:

[...] assim, aqui eu me sinto à vontade, nesse ponto... Olha que delícia, tipo assim, vamo lá, E. (fala o nome da entrevistadora), senta na área da piscina... Não é meu... Mas vamo falar assim, vamo colocá... Eu não sou dona da casa, mas sou filha da dona... (Margarida)

Por meio da Amizade-família, identificam-se jeitos de dizer sobre a figura polêmica da dona da pensão. Essa relação, muitas vezes ambígua, ganha aqui contornos de uma ação necessária, educativa, estabelecida por meio de uma idealização dessa figura, que aparece bem sucedida, no sentido de um exemplo a seguir.

P: Ai tem aquele prédio de apartamentos. Ai eu to na escadinha, tinha o pó... Ai... olho pro lado só vejo o carro da (fala o nome da dona da pensão) virar. Ai meu Deus (risos). Ai, balancei!

E: Balançou... (risos)

P: Ai já levantei, e já botei no meu short, né? Levantei.

E: Pra não perder tudo, né, danadinha. (risos)

P: O que tava na mão joguei fora... Ai eu fui lá falar com ela.

Ela não viu.

E: Aí o que ela falou?

P: Por um pouco. Por um triz. "Que que tava fazendo ali sentada?" 'Tava arrumando a minha sandália". (risos)... Ai!

E: Quê que a (dona da pensão) representa?

P: Aiiii... tipo assim... uma mãe, um pai, uma família que, como se diz? Pega muito no pé do filho. Pro bem.

E: Você sente assim?

P: Eu me sinto. Acho que todas também. (Perpétua)

O repertório também é usado quando se apontam os critérios que mostram o que muda da família de origem da 
travesti para esse novo sentido "inventado" pelas travestis, o qual marca positivamente o movimento de deixar a casa da família, pelo reconhecimento de que nesse novo "lar" é possível ser o que se escolheu.

E: E como é que é essas diferenças?

I: Aqui a gente tem... né? Porque a gente pode... porque aqui a gente é do jeito que a gente é, né? A gente fica à vontade. Entendeu? A gente anda pelada. Tira os peito pra fora, fica só de calcinha. Casa da mãe não. Por mais que seja a casa da mãe, mas tem a mãe, tem que ter respeito, tem o irmão. Eu acho que aqui é o lugar bem mais assim, pra nós morar. (Iris)

O repertório da Amizade-Família mostra um novo jeito de descrever as relações entre as travestis no espaço da casa-pensão, em especial, por incutir também a ideia de uma grande família de travestis. Os problemas aparecem, principalmente, quando as travestis negociam os sentidos do que é permitido e do que não é permitido na casa. Um dilema que é significado e construído por uma incongruência: se dizem pessoas crescidas que têm autonomia e, ao mesmo tempo, têm que seguir ordens da casa e da cafetina, como, por exemplo, a de não usar drogas.

\section{Amizade-segredo}

O repertório identificado como Amizade-segredo remete aos sentidos sobre as relações de amizade que se desdobram em relações amorosas e sexuais entre travestis. As falas explicitam algo velado, que não se resume à prática profissional da "suruba". Ele é composto por imagens e palavras como: afeto, ciúme, sexo, paixão, solidão, silêncio, agressão e distanciamento. É um repertório que requer um esforço para ser dito, portanto não é um repertório usado com naturalidade ou dito para qualquer interlocutor. Foi identificado em uso nas seguintes funções: 1) para dizer, com certo constrangimento, do "caso" e do "ficar" entre as travestis; 2) para descrever o ciúme, com nuances de brigas, vinculadas à negociação de um afeto positivo, demarcado pela paixão; 3) para explicar o porquê dessas relações serem construídas, apesar de não serem "aceitas".

O trecho a seguir aponta o uso velado que marca um interjogo de negação e afirmação para dizer da possível relação estabelecida:

E: Me conta um caso assim que você lembra.

A: Foi... eu dei um tapa na cara dela.

E: Deu um tapa na cara dela?

A: Tipo assim, a gente tinha um caso, entendeu?

$E$ : É, vocês namoraram?

A: Um caso... Sei lá se era fuleragem ou quê que era, sei lá... Isso passa... isso foi por causa de ciúme, entendeu?

E: Entendi. Mas isso pode acontecer...

A: É normal... Eu já falei pra você, eu não arrumo ninguém, eu sou muito possessiva, entendeu?

E: Hum hum. Mas você tem ela...

A: Não, hoje eu não gosto de ninguém...

$E$ : É, mas vocês já namoraram? Vocês duas

A: Não...

E: Foi? (A: Gargalhada, fica sem graça)

E: Ai vocêficou com outro rapaz?
A: Não, era tempo de rua, de programa, ela tinha ciúme, eu tinha ciúme, você saía com homem entendeu? Aquela palhaçada... (Açucena)

O namoro não é confirmado explicitamente, pelo menos, não nomeado como tal, mas se revela na interação, na busca por estabelecimento de sentidos entre a entrevistadora e a travesti. Vem explicitado, no caso, pela via da "fuleragem", um sentido que negativiza a vivência.

O uso desse repertório engloba, ainda, descrições que remetem ao ciúme, a brigas vinculadas à negociação de um afeto amoroso, também demarcado no trecho anterior. Não significam uma ruptura na relação, mas um arranjo que pode ser dito via um movimento de condenação da própria descrição, cheia de cuidado e ressalvas.

Os sentidos da Amizade-segredo são permeados por uma negociação que perpassa pelo valor de um sentido compartilhado de que travesti gosta de homem, mantendo uma "relação heterossexual" com seus parceiros. Esse repertório pode ser visto como uma denúncia que demarca a incoerência ou algo ruim a ser praticado e que (re)dimensiona os sentidos do que seria aceito nas práticas relacionais entre elas.

Esse repertório é usado, também para explicar o porquê dessas relações serem construídas, apesar de não serem "aceitas". Passa, assim, a compor os sentidos de afeto e as explicações em torno de como se dá o processo de apaixonarse por outra travesti:

E: Mas você acha que seria possivel isso? O que faz passar de amizade pro amor?

P: Ai... eu... a solidão.

E: Acha?

P. Sim. A solidão. Falta de amor por alguém. Muito sozinha...

Ai... quando de repente aparece aquela pessoa que... preenche esse vazio que você sente. Acaba sentindo amor mesmo. (risos)

E: Evocê já viu aqui na casa?

$P:$ Ah só elas mesmo.

E: De amiga. Mas tem...

P: Mas tem. É normal.

E: Humhum

P: Tem muitos casos. (Perpétua)

O repertório Amizade-segredo torna possível dar sentido a uma vivência solitária, que encontra ressonâncias nas falas sobre os homens e as relações possíveis de serem estabelecidas com esses parceiros tidos como "ideais". A desilusão amorosa e os sentidos de descrença frente aos relacionamentos românticos com homens recaem como um fator que dificulta a possibilidade de encontrar a paixão que seria aquela reconhecida e valorizada entre elas.

AAmizade-segredo é usada como que pela impossibilidade de manter um vínculo com homens, inclusive com os clientes. Restringe-se à possibilidade de amar aqueles que predominantemente teriam o vínculo desejado e compartilhado nesse universo, travesti-homem heterossexual. Além do uso desse repertório, as travestis ainda associam que a prostituição não combina com amor, evocando uma dupla justificativa para não viverem uma paixão: serem travestis e serem prostitutas.

O desgaste para falar da relação de amor entre as travestis situa, por outro lado, os significados que atribuem a si 
mesmas. Se não se significam, nesse momento, como pessoas que podem amar, prostitutas que poderiam ter afeto, como é plausível duas impossibilidades juntas e apaixonadas? Esse repertório traz uma relação dita, mas compartilhada de maneira velada pelas travestis amantes, eróticas e também solitárias.

\section{Amizade-uó}

O repertório Amizade-uó é composto por sentidos que traduzem os conflitos em torno das relações entre as travestis, e consigo próprias, ao longo da entrevista. São encontradas expressões e imagens como: agressão, fuxico, sujo, máfia, briga, machucar, confusão, anormalidade, dinheiro, drogas, pecado, passar fome, doença. O termo "uó" foi escolhido por ser êmico na linguagem Bajubá e ser usado pelas travestis para referir a algo ruim e problemático. $\mathrm{O}$ repertório é identificado nos seguintes momentos da entrevista: 1) naqueles em que as travestis falam das limitações e dificuldades dessa convivência tanto no espaço da casa, quanto no da rua; 2) quando as travestis apresentam a si mesmas de forma desqualificada, questionando a existência como travesti; 3) para demarcar um limite moral na convivência, delimitando o que é bom e o que é ruim;

No trecho a seguir, a travesti apresenta a relação entre elas marcada por adjetivos pejorativos sobre a convivência:

F: Que a gente vive numa... sei lá. É... é muito complicado pra mim falar isso. E é difícil. Mais... a gente vive num meio hipócrita. Num meio, sabe? Muito... sujo. A palavra correta é essa. Entendeu? Que por mais que você faça ali uma coisa certa. Você sempre é ruim.

E: Entendi. Mas como? Você falou sujo, né? Sujo como?

$F$ : Ai E. (fala o nome da entrevistadora)... Tudo que vem de maldade do próximo, pra mim, que é falsidade, a fofoca, é intriga, é enxerto. (Florinda)

O uso do repertório marca a negociação de falas que incluem as outras e as próprias interlocutoras pela "(im) possibilidade de existir" de forma digna, forjando um conjunto de sentidos ligados ao que é ruim, ao pecado, à anormalidade, depreciando o gênero travesti. A prostituição é descrita por meio desse repertório como uma prática que colabora ainda mais para o negativismo dessas relações e delas mesmas. O trecho a seguir aponta o desafio de encontrar um sentido positivo sobre as travestis a partir do uso desse repertório:

Ro: "Ehh traveco, êe João, que horas é o futebol?" meu Deus! Se gostosa é mil vezes, João é duas mil vezes. Ou seja, mais banaliza do que... Mas ai tem esse movimento gay que a gente faz, a parada, que ajuda apaziguar um pouco.

E: Entendi.

Ro: A gente tenta tapar o sol com a peneira.

E: Você acha que é tampar o sol...

Ro: Eu acho que daqui. É um processo gradativo, daqui um tempo quem sabe possa amenizar um pouco o preconceito... Mas nunca vai exterminar ele. Ele nunca vai ser extinto.

E: É, Rosa?
Ro: Eu acho que não, porque isso já vem de cultura, e logo mais porque você, a gente cresce com religião, é lógico, é desenvolvido com religião. E Deus já fala lá na bíblia, tal, tal, tal, isso já, você já é criado para aquilo, com aquela ideia: "Os afeminados não herdarão o reino do céu." (Rosa)

Por meio do repertório da Amizade-uó, termos associados à ambição, à maldade e à violência também são usados, mobilizando um estado de alerta na convivência. Ele aparece em momentos da entrevista em que as travestis encontram um limite moral, por reconhecerem o que seria bom e o que seria o ruim na convivência, prevalecendo o ruim:

C: Tem muita gente, tem bicha, que ela não nega droga na rua mas nega comida em casa.

$E: E^{2}$ ?

C: Encontra na rua cheirando, te oferece e tudo. Mas se tiver lanchando você pedir alguma coisa, fica louca... (Camélia)

O repertório Amizade-uó pode indicar uma contradição ao ser nomeado como amizade. Porém, a "Amizade" como termo idealizado positivamente não se coaduna com a leitura que as travestis usam nesse momento. O que ressaltam é um jeito de nomear as relações por meio de um vínculo difícil de lidar. Assim, a amizade-uó envolve usos que legitimam os sentidos religiosos, pecaminosos, anormais de dizer sobre as travestis e suas relações. Ao mesmo tempo, ele traz o compartilhamento de um fardo entre elas e a busca por um entre-lugar: ser travesti mas não ser a travesti que os outros (sociedade, religião, psiquiatria) traduzem, apesar de legitimar tal visão em alguns momentos.

\section{"Nem tudo é babado!": repertórios e existências em questão}

Nos repertórios interpretativos identificados se relacionam dois lugares discursivos: o primeiro, marcado pelos sentidos sobre as relações entre as travestis, e o segundo, pelos sentidos sobre si mesmas. A partir dos jogos que fazem entre esses dois lugares, as travestis legitimam suas relações de forma positiva ou as difamam.

Por meio do primeiro repertório apresentado, Amizadebabado, são destacados os critérios de amizade e as formas de convivência nos momentos de coletividade, nos efeitos positivos e construtivos desses vínculos. Esse uso se associa ao que as etnografias (Benedetti, 2005; Silva, 1993) apontam como o início do processo de montagem, em que as travestis se inspiram umas nas outras, tanto para construírem o feminino, quanto para se fazerem travestis, nos gestos, nas falas, no corpo. O critério da vulnerabilidade passa a ser um marcador importante de união.

No repertório Amizade-batalha, a prostituição aparece como um demarcador: ser prostituta é quase um sinônimo de ser travesti. $\mathrm{O}$ uso remete à importância da prostituição como espaço de sociabilidade e espaço de formação da travestilidade (Kulick, 2008; Pelúcio, 2007). Foi possível identificar, de igual forma, o uso de um sentido adaptativo e criativo do vínculo, que não idealiza o afeto entre elas e que reconhece os limites e os "deslizes" do grupo, possibilitando 
manter as relações sem expor a outra para, assim, não se expor - uma "colegagem" mediada pelo contexto.

No terceiro repertório, Amizade-família, as travestis constroem um sentido de pertencimento e de compartilhar a vida junto a outras travestis. Os sentidos utilizados nesse repertório sofrem influência dos moldes modernos que tendem a comunicar os vínculos construtivos pelo viés da fraternidade (Ortega, 2002). Tal uso sustenta e legitima a noção de família na significação de uma maternagem, nos encontros e festas de final de ano e de aniversário. Ao mesmo tempo, rompe com a noção tradicional de família, por ser possível conviver com a transgressão de um gênero sem o estranhamento do modo de vida escolhido. Portanto, configura uma família-travesti, num espaço em que o modo familiar tradicional é situado fora, mas não significa que é superado, constituindo dois modos válidos de ser família.

AAmizade-segredo, por outro lado, remete a sentidos em que a contradição de ser travesti e amar uma travesti encontra um léxico limitado, que não pode ser dito explicitamente. Aparece como um novo jeito de traduzir as travestis, agora nos seus relacionamentos amorosos. Conforme pontuou Foucault (1981, 2010), mais importante que permitir relações sexuais é o reconhecimento dos próprios indivíduos desse tipo de relação, no sentido de legitimar novos modos de vida. A marca da impossibilidade de se relacionar com outra travesti reflete um lugar solitário, em que o amor entre elas é subvalorizado.

A Amizade-uó, por sua vez, referenda esse não reconhecimento das relações, por compor usos pejorativos das travestis ao dizerem das relações e de si mesmas. Elas pontuam o pecado, a violência, a traição, o que ressoa no destino marcado por assassinatos, por ausência de uma adesão ao cuidado em saúde ou mesmo no questionamento da efetividade do movimento social para a mudança de suas realidades (Benedetti, 2005; Pelúcio, 2007).

De forma transversal, alguns contextos aparecem como marcadores, compondo os repertórios, tais como os espaços da rua, da casa e da vizinhança. A escola e outros espaços sociais, por outro lado, não aparecem como uma marca em nenhum dos repertórios, deixando sobressair que ainda não são léxicos construtores ou influentes nas relações entre elas.

Vale ressaltar que o uso dos repertórios é variável, ou seja, uma travesti pode vir a usar vários repertórios ao longo da conversa, uma vez que estão disponíveis socialmente e não localizados na pessoa em específico. Os repertórios estão associados ao processo conversacional, ou seja, mediante uma pergunta em dado contexto, as travestis podem usar um ou outro repertório, cujos efeitos podem ser diversos ou mesmo opostos. Trata-se de uma leitura questionadora de uma perspectiva linguística que pressupõe uma fala clara, lógica e objetiva sobre as relações. Não é possível, pois, reduzir as relações a apenas um dos repertórios identificados. A miscelânea de seu uso é que possibilita diferentes jeitos de dizer sobre as relações entre travestis e, por consequência, as diferentes implicações que carregam (Potter \& Wetherell, 1995).

Diante dos resultados, resgata-se um questionamento central: considerando que são os discursos hegemônicos de família, namoro, amizade que sustentam um tipo de descrição de quem somos nessa sociedade e nesse tempo histórico, como se daria isso para as travestis? As travestis, ao realizarem a mudança no gênero, acabam por afetar as estruturas de reconhecimento de si e, consequentemente, as relações de família, namoro e amizade são ameaçadas. Nesse processo, referendar um jeito de vivenciar a sexualidade destoante implica em novas formas de estabelecer esse reconhecimento, não necessariamente pela via de um apagamento da história e das relações pregressas, mas por meio de uma "lacuna relacional" que é ressignificada e reconstruída.

Nessa lacuna, as travestis convocam umas às outras no processo de (re)conhecimento de si e das novas relações, atenuando a abjeção (Butler, 1999) e, ao mesmo tempo, legitimando-a, pois a mencionada convocação não se mostra suficiente para assegurar uma existência reconhecida entre os demais sujeitos. Assim, na multiplicidade de sentidos, o universo se mantém num circuito marcado pela briga, pela conciliação, pela morte e pelo renascimento. São vocabulários diversos, de aproximações e de rupturas, que escolhemos nomear como "amizade", mas que podem encontrar outros léxicos, por ser uma lacuna ampla e diversa que não será preenchida apenas com esse recorte.

\section{Conclusão}

O desenvolvimento do estudo baseado na identificação dos repertórios interpretativos aponta os diversos sentidos de amizade vividos pelas travestis, da amizade babado à amizade uó, e permite associar os sentidos a formas de existências variadas. A atenção a essa diversidade de sentidos, por parte das travestis e dos profissionais que trabalham com elas, é fundamental para se pensar que as travestis, ao se dizerem associadas ao pecado, ao sujo, ao desprezível, se distanciam da possibilidade de reconhecimento quanto ao crescimento pessoal, à alteridade, ao cuidado em saúde, à busca pelo fortalecimento de uma rede política de garantia aos direitos e, por conseguinte, pela mobilização de mudanças em um processo de empoderamento. No entanto, se o foco discursivo começa a destacar a legitimidade de outros repertórios que não os que as colocam como pecadoras e monstros, outros jeitos de se portar, frente ao mundo e entre elas, podem aparecer e serem fortalecidos.

Assim, ao identificar os repertórios das relações de amizade, este estudo busca potencializar uma prática política e profissional que atente para a complexidade desse universo e que se responsabilize por tal complexidade. No âmbito profissional, pela via da afirmação de repertórios que visibilizem formas de vidas mais construtivas e legítimas para as travestis, amparando a (re)construção de uma autoria marcada pela abjeção. Tal afirmação pode se dar tanto em ações desenvolvidas diretamente junto à comunidade travesti, como na formação de profissionais que tratem de questões relativas a esse grupo. Em termos políticos, promovendo uma interlocução desses resultados com o planejamento e execução das políticas intersetoriais voltadas a essa população, no sentido de perceber que os repertórios usados por elas interferem diretamente na frequência às escolas, na adesão à saúde, na defesa pelo uso do nome social e na busca por outras oportunidades de trabalho. 


\section{Referências}

Benedetti, M. (2005). Toda Feita: O corpo e o gênero das travestis. Rio de Janeiro: Garamond.

Burr, V. (1995). An Introduction to Social Constructionism. New York: Routledge.

Butler, J. P. (1999). Corpos que pesam: Sobre os limites discursivos do sexo. In G. Louro (Ed.), O corpo Educado: pedagogias da sexualidade (pp. 151-166). Belo Horizonte: Autêntica

Butler, J. P. (2003). Problemas de Gênero: feminismo e subversão da identidade (R. Aguiar, trans.). Rio de Janeiro: Civilização Brasileira.

Cardoso, F. L. (2005). Inversões do papel de gênero: "drag queens", travestismo e transexualismo. Psicologia: Reflexão e Crítica, $18(3), 421-430$.

Carvalho, M. F. de L. (2011). A (im)possível pureza: medicalização e militância na experiência de travestis e transexuais. Sexualidade, Saúde e Sociedade, 8, 36-62.

Foucault, M. (1981). A amizade como modo de vida. Journal Gai Pied, 25, 38-39.

Foucault, M. (2010). Ditos e escritos V: Ética, Sexualidade, Política. Rio de Janeiro: Forense Universitária.

Garcia, M. R. V. (2009). Alguns aspectos da construção do gênero entre travestis de baixa renda. Psicologia USP, 20(4), 597-618.

Gergen, K. J. (1997). Realities and relationships. Cambridge: Harvard University Press.

Kulick, D. (2008). Travesti: Prostituição, sexo, gênero e cultura no Brasil. (C. Gordon, trans.). Rio de Janeiro: Editora Fiocruz.

Leite Junior, J. (2008). "Nossos corpos também mudam”: sexo, gênero e a invenção das categorias "travesti" e "transexual" no discurso científico. (Unpublished doctoral dissertation). Pontifícia Universidade Católica de São Paulo, São Paulo.

Nogueira, C. (2001). Contribuições do Construcionismo Social a uma nova Psicologia do Gênero. Cadernos de Pesquisa, 112, 137-153.
Nuernberg, A. H. (2008). Reflexões sobre gênero e Psicologia no Brasil. In M.C.de S. Lago, M. J. F. Toneli, A. Beiras, M. B. Vavassori \& R.C.F Muller (Eds.), Gênero e Pesquisa em Psicologia Social (pp. 19-33). São Paulo: Caso do Psicólogo.

Organização Mundial de Saúde. (2009). Classificação Estatística Internacional de Doenças e Problemas relacionados à Saúde (10 ed.). São Paulo: Editora da Universidade de São Paulo.

Ortega, F. (1999). Amizade e estética da Existência em Foucault. Rio de Janeiro: Edições Graal.

Ortega, F. (2002). Genealogias da Amizade. São Paulo: Iluminuras.

Paiva, V. (2008). A Psicologia redescobrirá a sexualidade? Psicologia em Estudo, 13(4), 641-651.

Pelúcio, L. M. (2007). Nos nervos, na carne, na pele: uma etnografia sobre a prostituição travesti e o modelo preventivo de Aids. (Unpublished doctoral dissertation). Universidade Federal de São Carlos, São Paulo.

Peres, W. S. (2005). Subjetividade das travestis brasileiras: da vulnerabilidade da estigmatização à construção da cidadania. (Unpublished doctoral dissertation). Universidade do Estado do Rio de Janeiro, Rio de Janeiro.

Potter, J., \& Wetherell, M. (1987). Discourse and Social Psychology. Londres: Sage.

Potter, J., \& Wetherell, M. (1995). Discourse Analysis. In J. A. Smith, R. Harré \& L. V Langenhove (Eds.), Rethinking methods in Psychlogy (pp. 80-92). Londres: Sage.

Silva. H. (1993). Travesti: a invenção do Feminino. Rio de Janeiro: Relume-Dumará.

Teixeira, F. B. (2008). L'Itália dei Divieti: entre o sonho de ser européia e o babado da prostituição. Cadernos Pagu, 31, 275-308.

Unger, R. K. (1979). Toward a redefinition of sex and gender. American Psychologist, 34, 1085-1094.

Weeks, J. (1999). O corpo e a sexualidade. In G. Louro (Ed.), $O$ corpo educado: pedagogias da sexualidade (pp. 35-83). Belo Horizonte: Autêntica. 


\title{
ERRATA
}

No artigo:

Rocha, Rita Matins Godoy, \& Raseira, Emerson Fernando. (2015). Sentidos sobre a Amizade Entre Travestis: Construção de Repertórios Interpretativos. Psicologia: Teoria e Pesquisa, 31(2), 239-247. https://dx.doi.org/10.1590/0102-37722015021853239247

Página 239,

Onde se lê:

\author{
Rita Matins Godoy Rocha ${ }^{1}$ \\ Universidade de São Paulo \\ Emerson Fernando Raseira \\ Universidade Federal de Uberlândia
}

\section{Leia-se:}

\author{
Rita Martins Godoy Rocha ${ }^{1, *}$ \\ ${ }^{1}$ Universidade de São Paulo, São Paulo, SP, Brasil \\ Emerson Fernando Rasera ${ }^{2}$
}

${ }^{2}$ Universidade Federal de Uberlândia, Uberlândia, $M G$, Brasil 